\title{
A GESTÃO DEMOCRÁTICA NA EDUCAÇÃO PROFISSIONAL AGROECOLÓGICA DO MST/PARANÁ: A EXPERIÊNCIA DA ESCOLA MILTON SANTOS
}

\author{
Democratic management in vocational education in agroecology mst / Paraná: the \\ experience of school Milton Santos
}

\author{
Lais Ribeiro dos Santos \\ Mestranda pelo Programa de Pós-Graduação em Educação da Faculdade de Filosofia e Ciências \\ UNESP/Campus Marilia \\ la_is.santos@hotmail.com
}

Artigo recebido em 30/06/2014 e aceito para publicação em 03/12/2014

http://dx.doi.org/10.12957/tamoios.2014.11705

RESUMO O presente artigo pretende demonstrar como é organizada a educação profissional em Agroecologia do MST no estado do Paraná. Compreendemos que a organização das escolas no MST acontece de forma democrática e identificamos que a Gestão Democrática (GD) é compreendida no MST como um princípio pedagógico fundamental, que visa direcionar a organicidade das escolas, por meio de ações e princípios como a autogestão, auto-organização dos estudantes, a participação efetiva e a inserção na coletividade. Dividimos este trabalho em quatro momentos: no primeiro momento apresentamos como se configura a educação profissional no MST, ressaltando que esta se insere na contratendência da educação profissional hegemônica; num segundo momento buscamos identificara entrada da Agroecologia na agenda do MST e compreender sua inserção na educação profissional do Movimento; posteriormente apresentamos como se configura a participação no seio deste Movimento e qual a concepção de GD instituída no MST; por fim apresentamos como a educação profissional agroecológica é organizada no centro/escola Milton Santos do MST/PR. Esta análise é parte dos resultados de uma pesquisa em desenvolvimento no âmbito do Mestrado em Educação e se pautou nos procedimentos da pesquisa bibliográfica, bem como, das entrevistas semiestruturadas e de observações diretas.

Palavras-Chave: Movimento dos Trabalhadores Rurais Sem Terra; Gestão Democrática; Agroecologia; Educação Profissional.

ABSTRACT This article aims to demonstrate how it is organized the professional education in Agroecology in the MST in the Paraná's state. We understand that the organization of the schools in MST happens democratically and we identified that the Democratic Management (DM) is understood in the MST as a fundamental pedagogical principle, which aims to direct the organicity of schools through actions and principles such as self-management, selforganization of students, effective participation and inclusion in the collectivity. We have divided this work into four stages: at first we present how to set up vocational education in the MST, emphasizing that this fits into the trend against the hegemonic professional education; secondly we seek to identify the entry of Agroecology in the agenda of MST and understand its insertion on vocational education of the Movement; posteriorly we present the configuration of participation with in this movement and what conception of DM instituted in MST; finally we present how agroecological vocational education is organized in the center/school Milton Santos MST/PR. This analysis is part of there sults of a research development with in the Master of Education and was based on the procedures of bibliographical research, as well the semistructured interviews and direct observations.

Keywords: The Landless Workers Movement; Democratic Management; Agroecology; Vocational Education. 


\section{INTRODUÇÃO}

Este trabalho é parte de uma pesquisa de mestrado $^{1}$ denominada Gestão Democrática e Participação na Educação Profissional Agroecológica do MST (PR): limites e possibilidades de uma educação emancipatória, visa abordar a questão da Gestão Democrática (GD) ${ }^{2}$ e da participação na educação profissional do Movimento dos Trabalhadores Rurais Sem Terra (MST) ${ }^{3}$, investigando através das práticas educativas em Agroecologia as principais características e tendências que apontem para uma perspectiva emancipatória de educação.

No decorrer deste trabalho tivemos como objetivo identificar e analisar como se organizam a Gestão Democrática e a participação no âmbito da educação profissional agroecológica, a partir das práticas desenvolvidas em um centro/escola do MST no município de Maringá no Paraná e ainda, verificar como se efetiva a participação dos alunos, professores e coordenadores na gestão desta escola.

Por meio de estudos anteriores (DAL RI, 2004, DAL RI; VIEITEZ, 2004; 2008), verificamos que o MST ao adotar uma concepção pedagógica própria e específica, institui em suas escolas o que ele denomina de Gestão Democrática. No entanto, depreendemos destas leituras que a Gestão Democrática não é homogênea nos acampamentos, assentamentos e escolas do Movimento, pois inúmeros fatores contribuem para variações na organização e gestão da vida nesses ambientes, ainda que sigam e se pautem em princípios comuns e apresentem características uniformes.

A hipótese da nossa pesquisa compreende que a GD e a participação na escola pesquisada, se organizam por meio de princípios e ações, como a autogestão, auto-organização, a participação efetiva e a inserção na coletividade, buscando a compreensão do ambiente educativo visando uma intencionalidade pedagógica específica.

Por Gestão Democrática entendemos o processo que possibilita a participação de todos os envolvidos na gestão da escola e do ambiente educativo, possibilitando através de ações e procedimentos diversos, uma participação efetiva de todos os sujeitos envolvidos, nas discussões e decisões pertinentes ao processo de gestão da escola.

Entendemos por autogestão o processo baseado na horizontalidade e que tem como procedimento a organização por meio de coletivos, conselhos e/ou comissões que a partir da participação de todos os sujeitos em assembleias coletivas com direito ao voto universal orientam e direcionam o ambiente educativo.

Por auto-organização compreendemos o processo de inserção da coletividade nas diversas instâncias de decisão, que visa através de práticas democráticas e dialógicas a organização dos espaços e práticas educativas.

Por participação efetiva e inserção na coletividade, entendemos as ações quepossibilitam a real participação dos envolvidos no processo de gestão da vida escolar, por meio da inserção na coletividade organizada (os coletivos, equipes e núcleos). Confabulamos que destes princípios e ações nascem germes de relações não capitalistas (BRIE, 2004), como afirmam (LIMA et al, 2012, p.9)

[...] a estrutura orgânica e o processo de gestão, por intermédio da autoorganização dos sujeitos, é a base que possibilita o planejamento, a organização e a realização do trabalho, que é desenvolvido por meio de relações de cooperação.

Dessa forma, para que o trabalho na escola aconteça e não seja somente uma distribuição de tarefas, mas seja trabalho concreto e socialmente útil é necessária uma estrutura combinada entre as pessoas e realizada através de uma ação coletiva. O MST em sua Pedagogia busca uma educação para a formação humana emancipatória, que contribua para superação das relações escolares tradicionais, baseadas em uma estrutura hierárquica e autoritária, que forma sujeitos subordinados dentro de uma estrutura própria do Estado capitalista.

No presente artigo, pretendemos demonstrar como se configura a educação profissional agroecológica no MST, a partir das experiências investigadas na pesquisa de mestrado mencionada e em decorrência de levantamento bibliográfico realizado sobre a referida temática. Temos como objetivo também, apontar a perspectiva democrática que se insere a educação profissional no MST, através do princípio da Gestão Democrática adotado e vivenciado nas escolas do Movimento. 
O MST é apontado por diversos autores como um movimento social (MS) de grande relevância, que se apresenta na contrahegemonia do capital, principalmente em relação à educação escolar, porque construiu ao longo dos anos determinados princípios educativos que objetivam compreender a totalidade das relações sociais e visam à formação integral do indivíduo (DAL RI, 2004). Das leituras de Guhur (2010) e Lima (2011) depreendemos que desde os anos 2000, o MST insere em sua agenda a Agroecologia em contraposição à produção de alimentos envenenados, buscando uma produção agrícola em consonância com seus objetivos enquanto MS o que levou à criação de escolas de educação profissional em Agroecologia, para formar técnicos dentro deste paradigma.

Entendemos que a educação oferecida nos centros/escolas de educação profissional do MST, está baseada na formação omnilateral do sujeito, buscando, através da ocupação da escola e apropriação dos conhecimentos historicamente produzidos, construir e direcionar o ensino sob uma intencionalidade política pedagógica contrária à conformação e reprodução das relações sociais capitalistas.

Buscamos neste artigo, portanto, apresentar uma experiência democrática, desenvolvida no âmbito da educação profissional em Agroecologia no MST/PR, por compreendermos que esta experiência é significativa no Movimento e para área educacional em geral, pois aponta características de uma Gestão Democrática, baseada em princípios educacionais contrários aos instituídos na escola estatal tradicional e ainda porque demonstra tendências educacionais que visam uma formação integral do sujeito, tendo como cerne a sociabilidade coletiva e a vivência a partir dos princípios da Agroecologia.

\section{A EDUCAÇÃO PROFISSIONAL NO MST - TENDÊNCIAS CONTRA HEGEMÔNICAS}

No final dos anos 1980 e início dos anos 1990, observamos no país um período de grandes contestações políticas e ideológicas, de disputa por espaços e pordemocratização dos espaços políticos e aparelho estatal, diversos segmentos da sociedade estiveram na vanguarda desses movimentos tendo destaque o Movimento Operário e no campo educacional o Movimento em Defesa da Escola Pública. No entanto, a configuração que se estabeleceu no âmbito da política educacional, em meados dos anos de 1990 se pautou "[...] por tendências conservadoras, as quais embora privilegiassem ora a racionalidade formal, ora a racionalidade técnica, sempre se fundaram na divisão entre pensamento e ação" (KUENZER, 2013, p.48). Das leituras de Felix Rosar (1989) e Paro (2002) identificamos que a política educacional brasileira e consequentemente o sistema educacional, sempre esteve assentado sobre uma contradição que se perpetua na escola até hoje, de um lado a escola clássica formativa de base científica e cultural para as classes dirigentes e do outro lado a pragmática, instrumental, adestradora, que promove a pseudo-participação e a formação profissional restrita para os trabalhadores.

Sendo assim, as políticas educacionais desse período direcionaram seus objetivos para a industrialização do país, as práticas educativas foram orientadas no sentido da modernização da empresa capitalista e seu desenvolvimento. Sob a égide da Revolução Verde o campo começa a aparecer como espaço de desenvolvimento industrial, mecanização, modernização e etc.

Kuenzer (2013, p.46) afirma que dentro desta reconfiguração do campo, são necessárias novas formações profissionais, ao analisar esta mudança paradigmática e suas influências no âmbito educacional a autora destaca, que este novo mercado globalizado exige cada vez mais qualidade com menor custo, demonstrando que a base técnica de produção fordista predominante no crescimento das economias capitalistas no pós Segunda Guerra até o final dos anos 1960, vai sendo aos poucos substituída e superada por um processo de trabalho resultante de um novo paradigma tecnológico, apoiado essencialmente na microeletrônica e com a característica principal de flexibilidade.

$\mathrm{Na}$ contramão desse sistema educacional brasileiro, no final do século XX, ressurgem movimentos das camadas populares que estão nas escolas públicas ou que buscam construir uma pedagogia voltada aos interesses da classe trabalhadora, como o caso das escolas situadas em assentamentos da reforma agrária, as itinerantes dos acampamentos do MST, bem como os centros/escolas de educação profissional do próprio MST. Caldart (2010, p.238) afirma que a educação profissional do campo está embutida de novos desafios, 
[...] o desafio é pensar a educação profissional como formação específica para o trabalho que visa superar a dicotomia entre trabalho manual e trabalho intelectual e atender as exigências de inserção de todas as pessoas no trabalho socialmente produtivo próprio de seu tempo histórico. Trata-se de preparar para um trabalho cada vez mais complexo, sem ignorar as inovações tecnológicas, mas fazendo sua crítica ( e superação) desde o princípio de que as tecnologias que nos interessam são as que efetivamente se constituem como forças produtivas e não destrutivas da vida.

Portanto ao debater a formação profissional o MST está discutindo a apropriação pelos trabalhadores de conhecimentos e habilidades necessários para o desempenho de funções que o integrem em processos produtivos próprios, necessariamente esta formação está circunscrita na materialidade do trabalho no campo, na compreensão do comodo porque e de quais as consequências para a sociedade, está baseado numa educação que possibilite a leitura da realidade, mas que a faça sob a óptica da classe trabalhadora, dessa forma, a formação profissional que o MST assume como parte de sua luta por educação nos espaços da Reforma Agrária está relacionada à produção e reprodução do próprio Movimento, como processo de resistência, por isso é necessariamente contrária à formação profissional tradicional que visa à integração no mercado de trabalho.

Guhur (2010) destaca algumas características e concepções pedagógicas que a Educação Profissional do Campo assume, dentre elas a do MST: a) a coletividade como principal foco de intencionalidade; b) a gestão democráticaque envolve a participação de educandos e educadores de forma organizada, em todo o processo pedagógico; c) a concepção de formação humana, que não se restringe ao processo de ensino, mas integra o trabalho produtivo e o Movimento Social como elementos também formadores.

Temos que a educação profissional do MST, assim como, os demais cursos formais promovidos pelo Movimento, assumem certa uniformidade de organização e funcionamento, ainda que com uma relativa autonomia pedagógica, respaldada pela LDB. Guhur (2010, p.154) ao analisar a educação profissional agroecológica do MST no Estado do Paraná aponta que o objetivo é construir a escola diferente, tendo como referência as práticas educativas construídas pelo Movimento e destaca,

[...] a experiência de referência é sem dúvida aquela acumulada pela Escola Josué de Castro, do Instituto Técnico de Capacitação e Pesquisa da Reforma Agrária- ITERRA, em Veranópolis-RS, primeira escola formal do MST. Assim, a elaboração de qualquer Projeto Político e Pedagógico das escolas do MST se baseia nos documentos do ITERRA, em especial o caderno n. 2, intitulado "Projeto Pedagógico", e o caderno n. 6, intitulado "Método Pedagógico" (ITERRA, 2001, 2004), que procuram traduzir os princípios filosóficos e pedagógicos da educação no MST (GUHUR, 2010, p.154)

Entendemos que certa uniformidade apresentada nos cursos se baseia no princípio da intencionalidade pedagógica apontado como um dos objetivos da educação do MST. Alguns elementos básicos formadores do Método Pedagógico, apresentado nos cadernos do ITERRA (2004), podem ser destacados, pois orientam as práticas pedagógicas na educação profissional em Agroecologia, e são eles: a alternância; os tempos educativos; o trabalho; a gestão democrática, e a pesquisa.

Relembramos que o projeto de Educação Profissional que o MST começa a articular a partir do debate da Educação do Campo em meados dos anos de 1997 e 1998, denominado Por uma Educação do Campo está circunscrito na luta por afirmação do campo enquanto espaço de vida e na compreensão e negação do modelo educacional hegemônico, mas principalmente está vinculado a um Projeto Popular de Desenvolvimento do Campo, que pretende ser uma contribuição à construção de um Projeto Popular para o Brasil (GUHUR, 2010).

A educação profissional circunscrita no âmbito de um MS como o MST está assentada sobre bases educacionais diferenciadas, pois compreende a educação profissional como um braço para o desenvolvimento do campo, atribuindo a esta formação o objetivo de qualificação profissional que visa à capacitação dos sujeitos Sem Terra para a realização de funções que contribuam para o 
desenvolvimento do campo como espaço de vida e que tenham em vista as áreas e espaços conquistados pela reforma agrária (RA), assim essa formação não está relacionada a colocações no mercado de trabalho e não se apresenta com objetivos hierárquicos e individuais, sendo seu objetivo principal a formação para a coletividade e participação no próprio Movimento.

\section{A AGROECOLOGIA NO CONTEXTO DA EDUCAÇÃO PROFISSIONAL DO MST}

Depreendemos das leituras (GUHUR, 2010; LIMA, 2011; LIMA et al, 2012; GUHUR; TONÁ, 2012) que a partir dos anos 2000 o MST e a Via Campesina têm ampliado a compreensão acerca da Agroecologia como parte de sua estratégia política e do modo de organização da produção da vida no campo.

A agroecologia entra formalmente na agenda do MST nos anos 2000 em função de inúmeras lutas contra o uso de agrotóxicos, contra o plantio de transgênicos e por meio da realização de pesquisas científicas por grandes corporações, danosas ao ser humano e ao meio ambiente. Em contraposição a este paradigma científico e a esta forma de produção o MST passa a incentivar a transição para a produção de alimentos saudáveis. Desde 2002, o Movimento tem desencadeado ações para consolidar práticas educativas em Agroecologia visando à formação política e técnica dos sujeitos Sem Terra. Esta proposta levou ao surgimento de mais ou menos 26 escolas de Agroecologia do Movimento em todo o Brasil, com a intenção de formar técnicos voltados para a criação das condições gerais de produção e reprodução da Agroecologia.

Verificamos que a Agroecologia tem sido entendida pelo Movimento como um campo de conhecimento de caráter multidisciplinar que subsidia trabalhadores organizados no campo com princípios e conceitos ecológicos para o manejo e desenho de agroecossistemas sustentáveis. Sobre isso, Caporal e Costabeber (2002) observam que nenhum produto será verdadeiramente ecológico se a sua produção estiver sendo realizada à custa da exploração da mão de obra. Ou ainda, quando o não uso de certos insumos para atender convenções de mercado estiver sendo compensado por novas formas de esgotamento do solo ou de degradação dos recursos naturais. Nesta concepção, Guhur e Toná (2012, p.66) afirmam

a agroecologia inclui: o cuidado e defesa da vida, produção de alimentos, consciência política e organizacional (Via Campesina e Movimento dos Trabalhadores Rurais Sem Terra, 2009). Compreende-se que ela seja inseparável da luta pela soberania alimentar e energética, pela defesa e recuperação de territórios, pelas reformas agrária e urbana, e pela cooperação e aliança entre os povos do campo e da cidade.

E continuam:

A agroecologia se insere, dessa maneira, na busca por construir uma sociedade de produtores livremente associados para a sustentação de toda a vida (Via Campesina e Movimento dos Trabalhadores Rurais Sem Terra, 2006), sociedade na qual o objetivo final deixa de ser o lucro, passando a ser a emancipação humana (GUHUR; TONÁ, 2012, p.67).

Destas ações foram criados cinco centros/escolas ${ }^{4}$ de formação do MST no Paraná que se apresentam na dianteira do debate da Agroecologia. Lima et al (2012) atesta que os fundamentos teóricos e metodológicos dos centros/escolas de formação do MST/PR estão vinculados aos princípios filosóficos e pedagógicos da educação e da Pedagogia do Movimento Sem Terra ${ }^{5}$ que através da luta pela terra e por transformações na sociedade articula e compreende a educação enquanto processo formativo emancipatório, cuja sistematização é fruto da reflexão sobre a sua práxis política educativa, a partir de três fontes fundamentais: a Pedagogia Socialista, a Educação Popular e a Pedagogia do Movimento. Nesta perspectiva o ser humano é concebido como ser social e sujeito histórico, protagonista dos processos formativos, atuando de forma crítica em relação ao movimento histórico, dialético e contraditório de seu modo de vida social.

Observamos também, que para a Pedagogia do MST, a educação tem compromisso político com a transformação social em consonância com a organização e o fazer educativo, sendo assim, a formação dos Sem Terra e as práticas educativas em Agroecologia não se resumem às atividades 
desenvolvidas na escola, mas está forjada também, nas matrizes da formação humana, conforme identificamos na Pedagogia do Movimento: "[...] o principio educativo do trabalho, a práxis social e a história”. (LIMA apud CALDART, 2004, p.42)

A constituição de centros/escolas de Agroecologia do próprio Movimento tem a ver com a transição que o MST assume, no âmbito da produção para uma produção agroecológica que respeite os seres humanos e o meio ambiente, mas principalmente com a intencionalidade política pedagógica do Movimento, que busca um projeto emancipatório para a classe trabalhadora, sendo assim, a Agroecologia é componente crucial para a problematização do MST entorno do que fazer, enquanto um MS circunscrito numa lógica de sociedade, mas que se coloca contrário a ela, a Agroecologia apresenta ao próprio MST a discussão da organização da vida visando à continuidade da vida no campo, pois demonstra a barbárie do capital no campo e incita os sujeitos Sem Terra a se posicionarem.

\section{A PARTICIPAÇÃO DOS SUJEITOS SEM TERRA E A GESTÃO DEMOCRÁTICA}

Fernandes (apud GUHUR, 2010, p.77) afirma que uma das dificuldades que o Movimento enfrenta no início do século está relacionada à participação dos sujeitos Sem Terra nas escolas, nos assentamentos e na sociedade em geral, devido ao crescimento das famílias e abrangência geográfica do Movimento sua antiga organicidade encontra dificuldades para implementar o princípio da direção coletiva, que é um dos princípios norteadores do Movimento.

Segundo Guhur (2010) é a partir dos anos 2000que a organicidade passa a ser um tema encarado como Desafio Permanente do MST, visto que sua organização passa a ser considerada como verticalpropõem-se uma estrutura horizontal que possibilite ao maior número de pessoas/famílias o envolvimento nos processos de decisão e que estejam em frequente mudança dentro das instâncias que compõem esta estrutura organizativa, buscando garantir maior participação dos sujeitos nas brigadas, núcleos de base e coordenações, garantindo dessa forma um processo importante de GD nas escolas e nos assentamentos do MST.

Ao falar em organicidade o MST está se referindo ao processo que permite a relação de cada parte com o todo. Esse processo não se resume às áreas e instâncias do Movimento circunscritas nas escolas, mas a todo o conjunto do MST. No entanto, em suas escolas, o MST instaura um processo de GD, que permite o cuidado com esta organicidade e que visa manter sua estrutura em movimento.

Caldart (2004, p. 256-257 grifos da autora) aponta que

[..] a expressão organicidade indica no Movimento o processo através do qual uma determinada ideia ou tomada de decisão consegue percorrer, de forma ágil e sincronizada, o conjunto das instâncias que constituem a organização, desde o núcleo de base de cada acampamento e assentamento até a direção nacional do MST, em uma combinação permanente de movimentos ascendentes e descendentes capazes de garantir a participação efetiva de todos na condução da luta em suas diversas dimensões.

Essa é, aliás “ a própria noção de democracia do MST" (CALDART, 2012, p.257). Dessa forma, as diversas demandas das famílias Sem Terra podem percorrer o caminho até as instâncias nacionais, estaduais e o inverso também pode acontecer, garantindo uma articulação dos projetos, definições e objetivos do Movimento com toda a base.

A Gestão Democrática é um dos princípios pedagógicos do MST e se insere na regra "[...] todos gerindo, no comando do processo (ITERRA, 2004, p.30)". Tem a ver com o processo pelo qual os sujeitos constituem a coletividade e atuam sob uma intencionalidade pedagógica que tem por objetivo descaracterizar práticas hierárquicas e autoritárias, constituindo uma nova sociabilidade que se quer democrática.

A GD demanda uma estrutura organizativa nas escolas que combine educadores e educandos na participação da gestão de todo o processo educativo. Segundo o caderno do ITERRA (2004, p.30) "[...] não basta refletir e debater sobre a gestão: é necessário vivenciar espaços de participação democrática, educando-se para a democracia social".

O MST pretende em suas escolas, por meio da GD superar práticas de caciquismo, 
presidencialismo e mandonismo tão instauradas e arraigadas na nossa sociedade, e por outro lado, também, superar a ideia do assembleísmo como única alternativa de participação.

[...] O desafio é garantir a "radicalização da gestão" através da participação real dos educandos (por escolha de representantes e através da autogestão) em todas as fases do processo (da análise, decisão, planejamento, execução, avaliação) e em todas as instâncias de gestão (ITERRA, 2004, p.31)

Duas dimensões são consideradas fundamentais no processo de GD na educação, sendo elas: a) direção coletiva, que compreende a participação efetiva da comunidade na gestão da escola, bem como de seus participantes diretos; b) participação de todos envolvidos no processo de gestão, na tomada de decisões, no planejamento e avaliação dos resultados. Por meio da organização em instâncias de participação.

Neste sentido, compreendemos que a GD no MST, não está especialmente relacionada à gestão da escola, mas diz respeito a um processo mais amplo que engloba toda a dinâmica do Movimento, considerando todas as relações sociais que são desenvolvidas nesse movimento de luta.

Assim, organicidade e Gestão Democrática assumem uma linha muito tênue no Movimento, podendo ser confundidas e até tomadas como sinônimos, no entanto, apesar de se constituírem por meio do mesmo princípio se configuram na prática de forma diferenciada. Compreendemos que os dois conceitos se complementam, tanto em relação a sua conceituação como configuração prática. Para um efetivo processo de GD, entendemos que é necessária uma organicidade, uma vez que esta possibilita a interação de todos os integrantes do MST em sua dinâmica, e no âmbito da escola, possibilita o movimento necessário ao cotidiano escolar numa perspectiva de participação efetiva de seus membros, o que tem por princípio alterar as relações sociais na escola.

\section{A ESCOLA Milton SANTOS E A GESTÃo DEMOCRÁtica NA EDUCAÇÃo PROFISSIONAL AGROECOLÓGICA}

A Escola Milton Santos (EMS) é um centro/escola de educação profissional em Agroecologia do MST, criado em 10 de Junho de 2002 como parte do esforço do Movimento por criar as condições materiais de implementação da Agroecologia nos assentamentos e acampamentos do MST, e também do esforço de conquistar espaços de luta pela Reforma Agrária e por uma transformação social mais ampla.

Segundo Guhur (2012 s/p) a representação legal da EMS, se constitui como:

uma escola popular, não estando oficialmente integrada à rede pública de ensino. Inicialmente vinculada ao Instituto Técnico de Educação e Pesquisa da Reforma Agrária-ITEPA, a EMS é hoje legalmente representada pela Associação de Trabalhadores na Educação e Produção em Agroecologia Milton Santos-ATEMIS, fundada em janeiro de 2007. A ATEMIS é composta por pequenos agricultores, camponeses, educadores e educandos do campo do Estado do Paraná, e tem por objetivo geral estimular o desenvolvimento comunitário e cultural, o desenvolvimento agrícola, a agroecologia e o desenvolvimento sustentável, desenvolvendo atividades de educação, capacitação e pesquisa, conforme explicitado em seu estatuto.

O objetivo geral da escola Milton Santos é,

[...] se constituir como um Centro de Educação do Campo em vista de elevar o nível de formação política e cultural, educação e capacitação de jovens e adultos do campo. Participar na construção de um projeto de humanização das pessoas que possibilite formação de sujeitos sociais na construção de um projeto de desenvolvimento do campo e do país comprometido com a soberania nacional, com a Reforma Agrária e outras formas de desconcentração da renda e da propriedade, com a solidariedade, com a democracia popular e com o respeito ao meio ambiente (ESCOLA MILTON 
SANTOS, 2003).

Conforme documentos da Escola Milton Santos (2003), assim como os demais cursos e escolas do Movimento, o Projeto Político e Pedagógico da escola foi construído tendo em vista a Teoria da Organização, as Normas Gerais do MST e o MétodoPedagógico sistematizado pelo Instituto de Educação Josué de Castro-IEJC.

$\mathrm{Na}$ EMS, desde sua inauguração moram pessoas ligadas ao Movimento nas suas diversas instâncias, seja acampamento, assentamento, cooperativa ou voluntários. Os moradores permanentes constituem um Núcleo de Base da escola, denominado de NB Milton Santos, dentro deste NB existem quatro setores de atuação, quais sejam: o setor administrativo, pedagógico, de infraestrutura e de produção, cada setor tem suas equipes de trabalho para o desenvolvimento das tarefas relacionadas a cada setor, por exemplo: setor administrativo - frente de secretaria, finanças e etc.

Ao setor pedagógico, que é nosso objeto direto de estudo, está integrado o Coletivo Político Pedagógico (CPP), responsável por toda a administração pedagógica da escola, parcerias com Institutos, Universidades e Estado.

A estrutura orgânica que orienta a organização e a gestão da escola e das turmas que compõem a escola seguem as direções e normais gerais do MST, mas principalmente, se respaldam nas experiências acumuladas pelo MST, no âmbito da educação profissional, do IEJC em Veranópolis que estão sistematizadas nos cadernos do ITERRA (2004; 2008).

Lima (2011) aponta que nos processos-educativos do MST são instituídas as coordenações e os coletivos objetivando a formação dos sujeitos Sem Terra, organizando e direcionando o tempo escola, mediante as estratégias pedagógicas do Movimento e por meio do processo de GD, entendido sob as bases da auto-organização e do trabalho socialmente útil. Neste sentido,

Buscam a participação de todas as pessoas, educandos e educadores, na organização e construção dos processos formativos que abrangem as atividades da educação escolar - cursos formais - o trabalho na produção e os trabalhos de serviços gerais necessários à organização na vida coletiva (LIMA, 2011, p.123)

Alguns coletivos são instituídos na educação profissional do MST, a fim de cumprir esta tarefa pedagógica de possibilitar a participação efetiva de todos na gestão da escola e garantir a inserção na coletividade do Movimento. E podem ser observados a partir da sistematização abaixo:

\begin{tabular}{|c|c|}
\hline Coletivos & Funções atribuídas \\
\hline $\begin{array}{c}\text { Coletivo de } \\
\text { Acompanhamento } \\
\text { PolíticoPedagógico (CAPP) }\end{array}$ & $\begin{array}{l}\text { O CAPP "[...] tem como finalidade garantir as linhas } \\
\text { políticas pedagógicas, sendo uma instância de } \\
\text { acompanhamento permanente dos educandos. Tem por } \\
\text { função garantir a implementação das linhas políticas e dos } \\
\text { princípios organizativos do Movimento, acompanhar, } \\
\text { avaliar e discutir o processo pedagógico do curso com as } \\
\text { turmas". }\end{array}$ \\
\hline $\begin{array}{l}\text { Coletivo da Coordenação } \\
\text { Geral do Curso (CNBT) }\end{array}$ & $\begin{array}{l}\text { "[...] formada pela coordenação político pedagógica e } \\
\text { pelos (as) coordenadores (as) dos núcleos de base, os (as) } \\
\text { quais terão a responsabilidade de coordenar as atividades } \\
\text { definidas coletivamente". } \\
\text { "Tarefas da Coordenação: garantir a unidade e disciplina } \\
\text { do grupo, garantir a realização das atividades, coordenar o } \\
\text { tempo aula, garantir o funcionamento e as tarefas dos NBs, } \\
\text { discutir os aspectos pedagógicos referentes ao curso, à } \\
\text { turma e à Escola [...]". }\end{array}$ \\
\hline
\end{tabular}




\begin{tabular}{|c|l|}
\hline Coletivo dos Núcleos de & $\begin{array}{l}\text { "Tem por função e tarefa de eleger a coordenação geral da } \\
\text { Turma em cada TE: apresentar propostas à coordenação } \\
\text { geral sobre o funcionamento do curso e da escola } \\
\text { garantindo o cumprimento das decisões coletivas; atuar } \\
\text { Base (NBs) } \\
\text { disciplina, fortalecendo a consciência organizativa e a } \\
\text { participação de seus integrantes em todas as atividades, } \\
\text { incluindo a disciplina, valores, relações humanas; } \\
\text { coordenar atividades conforme a organização e } \\
\text { cronograma de trabalho". }\end{array}$ \\
\hline Equipes de trabalho & $\begin{array}{l}\text { "São as instâncias responsáveis pela realização de tarefas } \\
\text { específicas para o funcionamento interno do curso. Sendo } \\
\text { composto pelas seguintes equipes: Disciplina, Saúde, } \\
\text { Mística e Esporte e Lazer, Relações Humanas, } \\
\text { Comunicação e Cultura, Higiene e Saúde, Relatoria e } \\
\text { Memória". }\end{array}$ \\
\hline
\end{tabular}

Fonte: Organizado e adaptado por Lima (2011).

Assim, na EMS temos a organização das turmas por meio dos núcleos de base de turma que são formados no início de cada curso, os NBstêm aproximadamente sete educandos, dessa forma, a quantidade de NBs em uma turma depende da quantidade de educandos. Os NBs permitem o diálogo e a divisão das tarefas entre os educandos, sendo que em cada NB são formadas equipes de trabalho que se organizam entre representantes para distribuir as atividades da semana.

As equipes de trabalho são formadas por dois tipos (comum e de turma) sendo que as comuns a toda a escola, são as de: disciplina; mística, comunicação e cultura; esporte, lazer e saúde; e as específicas da turma são as de: relatoria e memória e finanças. Cada equipe tem dois representantes também, quando possível, formados por um educando e uma educanda.

No início de cada turma é constituído um coletivo específico, denominado Coletivo de Acompanhamento Político Pedagógico (CAPP) que visa administrar a relação entre os diferentes segmentos (professores, educandos, moradores permanentes da escola e comunidade externa) este coletivo também tem a função de acompanhar o desenvolvimento da turma, observando questões pontuais de rotina escolar, mas também articulando esses segmentos em torno do desenvolvimento do projeto político pedagógico do curso.

Os representantes dos NBs da turma, juntamente com os representantes das equipes, mais um representante do NB Milton Santos e um coordenador (a) do CAAP, integram a Coordenação Geral de Núcleos de Base (CNBT), que se encontram semanalmente para discutir os assuntos relacionados ao curso.

Quanto a participação efetiva de todos os envolvidos no processo de gestão da escola, destacamos:

\section{Quanto aos educandos,}

Compreendemos que a escola Milton Santos, se constitui enquanto um centro de difusão e instituição da Agroecologia, atuando nas diversas áreas e níveis escolares, recebendo educandos de várias regiões do país, mas principalmente os oriundos da região sul.

Os educandos oriundos de diversas regiões, bem como de diversas instâncias do Movimento (acampamento, assentamento, ocupação e cooperativas) permanecem na escola para a realização do TE podendo variar a permanência destes de acordo com o curso. Quando chegam à escola passam por uma etapa preparatória para o curso que irão participar, recebendo instruções acerca da escola, da organicidade e do projeto político pedagógico. Após a etapa preparatória quando efetivamente começam o curso pretendido são inseridos nesta estrutura organizacional mencionada acima, passando a atuar nas diversas áreas da escola, tanto de cuidado e manutenção desta, como relacionado às questões mais intrínsecas aos cursos.

As instâncias que compõem a estrutura orgânica da escola são basicamente as relacionadas na tabela acima, as que se relacionam diretamente aos cursos e aos educandos estão no âmbito dos NBs 
de turma e das equipes e frentes de trabalho. É importante ressaltar que as equipes de trabalho são formadas de acordo com a turma e com a necessidade da escola, não sendo uma estrutura fechada e rígida, mas em constante movimento.

Cada frente de trabalho é pensada tendo em vista a manutenção da escola, mas principalmente a relação entre teoria e prática que é um dos princípios norteadores da Pedagogia do MST. Sendo assim, nos cursos técnicos em Agroecologia teremos frentes de trabalho que se relacionam amplamente com o Setor de Produção da escola, por meio do tempo trabalho e da vivencia permitida pelo curso. No entanto, em cursos como o Médio Integrado e principalmente na Pedagogia, teremos outras frentes de trabalho sendo pensadas pelo CPP da escola, pois, a carga horária desses cursos é maior, portanto a rotina mais acelerada e em relação ao curso de Pedagogia, a questão da relação da teoria e prática, se estabelece através de outros setores da escola, como o Pedagógico, o de Infraestrutura e o Administrativo, não tendo tanta ênfase no Setor de Produção.

Neste sentido, a participação dos educandos na escola, acontece de forma efetiva por meio do processo de Gestão Democrática instaurado na EMS, através das instâncias de decisões os educandos vivenciam sua formação de forma ativa desenvolvendo espaços de coletivização e de cooperação.

No que diz respeitoàs decisões mais amplas dos cursos e da escola, como a gestão financeira $\mathrm{e}$ a relação com os parceiros institucionais, a participação dos educandos também acontece, mas de forma restrita, uma vez que estes assuntos são discutidos no âmbito do Conselho Político da EMS e da Coordenação Político Pedagógica que se constituem com a participação dos moradores permanentes tendo representação dos Setores da escola e dos educandos.

A estrutura orgânica por meio da organicidade do Movimento e principalmente sob o princípio da Gestão Democrática tem possibilitado uma formação diferenciada para estes educandos, tendo em vista que não estão se educando somente para uma posição profissional, mas para se posicionarem politicamente frente à sociedade capitalista.

\section{Quanto aos educadores,}

Os cursos realizados na escola acontecem por meio de parcerias com instituições de ensino, em nível do PRONERA (Programa Nacional de Educação na Reforma Agrária), tais como: UEM, UTFPR, UNIOESTE e outras.

Os educadores que lecionam nestes cursos podem ser vinculados a estas instituições, podendo ter ou não relação direta com o MST, na maioria dos casos, os educadores são do próprio Movimento, militantes que atuam junto ao Setor de Produção do MST, são direcionados aos centros/escolas para lecionarem nos cursos, o que possibilita uma maior aproximação com os objetivos políticos pedagógicos do Movimento.

A maior dificuldade relacionada à GDna escola tem a ver com a rotatividade de professores e professoras e com a ausência destes no cotidiano integral da escola, pois trabalham em regimes de contratação com cargas horárias pesadas e atribuladas. Os educadores não permanecem na escola nos contraturnos, nem constituem ou integram os coletivos existentes na escola, neste sentido, os educadores têm executado as funções pertinentes aos seus cargos, mas ainda não compõem o processo de GD vivenciado na escola de forma ampla e profunda.

\section{Quanto aos coordenadores,}

Na escola Milton Santos, como também, em outros centros/escolas de educação profissional do MST, a organização por coletivos e núcleos de base possibilita uma participação efetiva dos coordenadores no processo de GD da escola, e ainda, a desierarquização dos cargos e funções na escola, pois os coordenadores ao comporem os coletivos organizam e administram a escola juntamente com os moradores permanentes e os educandos. A participação dos coordenadores tem destaque na mediação dos educandos com os educadores e principalmente as ações que desenvolvem visando que a dinâmica organizacional da escola aconteça, orientando os educandos quanto aos NBs, os setores, as coordenações.

Quanto aos moradores permanentes, 
Na escola, quase sempre moram pessoas que de forma direta se relacionam com a educação no MST, dessa forma, os moradores que constituem o NB Milton Santos, foram para lá ou no processo de construção da escola ou após sua construção. Assim, estes moradores, integram os diferentes setores da escola, mas os que se relacionam diretamente ao setor pedagógico podem vivenciar e organizar este processo de GD de forma mais efetiva, constituindo as equipes de trabalho e os coletivos.

Observamos, que com esta dinâmica organizacional o MST, especialmente na escola Milton Santos, visa instaurar práticas educativas que estejam em consonância com seu projeto político enquanto Movimento Social, que objetiva construir as bases para uma transformação social.

Entendemos que a concepção de GD do MST é radical, pois, apresenta características que visam uma sociabilidade antagônica a do capital, buscando por meio da inserção de todos os envolvidos no processo de luta pela terra e consequentemente de todos os envolvidos nos processos de formação e qualificação profissional, estabelecer relações de trabalho e convívio permeados por princípios como a cooperação, a auto-organização e a autogestão.

Por meio da inserção dos indivíduos nessa organicidade coletiva, buscam as bases para alteração das relações sociais, atuando na perspectiva de um vir a ser, mas construindo, lutando, trabalhando coletivamente pelos ideais da classe trabalhadora, vislumbrando projetos de vida que reafirmem esta classe e não a oprima. No âmbito da GD entendemos que se trata de formar sujeitos políticos emancipados, capazes de atuar autonomamente, buscando através da coletividade, uma sociabilidade que supere e esteja em constante contraposição a sociabilidade vivenciada por estes sujeitos quando aindainseridos e subordinados a escola estatal tradicional.

\section{CONSIDERAÇÕES FINAIS}

Ao analisarmos a GD nas escolas do MST, principalmente as escolas de educação profissional no Paraná, depreendemos que a organicidade e a gestão dessas escolas seguem as orientações gerais do MST em relação à estrutura e forma organizacional das escolas, dessa forma, apresentam uma configuração de GD própria do Movimento.

Em relação à escola Milton Santos, verificamos segundo Guhur (2012) que a escola segue as determinações e instruções gerais do MST, mas principalmente, nasce respaldada pelas experiências acumuladas no Movimento no âmbito da educação profissional, principalmente as do IEJC, sistematizadas pelos cadernos do ITERRA (2004; 2006).

No que tange à hipótese de nossa pesquisa, destacamos que a Gestão Democrática apresentada na escola Milton Santos do MST se baseia em princípios e ações, que tem como cerne o desenvolvimento de uma sociabilidade coletiva, baseada na autogestão, entendida como projeto de sociedade, que ainda que não se desenvolva em sentido restrito permeia os documentos e as práticas educativas na escola; na auto-organização dos estudantes, através da instauração de coletivos e formas de auto-organização pertinentes ao processo democrático e que viabilizam a inserção dos educandos numa prática de autoformação; quanto à participação efetiva e a inserção na coletividade, observamos que as condições são construídas no Movimento para a participação real dos sujeitos tendo como objetivo principal a formação critica dos sujeitos Sem Terra, dessa forma, a inserção na coletividade contribui para a vivência dos jovens e adultos que adentram a escola de práticas educativas que possibilitam e instigam a cooperação, a socialização e a formação humana mais ampla.

Concluímos que ainda que existam limites (e muitos) para a instauração de um processo democrático nas escolas, e principalmente em uma escola de educação agroecológica no contexto do MST, a escola Milton Santos vem desempenhando um papel fundamental de formação humana baseada em princípios que vislumbram um projeto de sociedade e um projeto popular de campo. 


\section{NOTAS}

1 - Esta pesquisa de Mestrado conta com o financiamento da Fapesp sob processo de no 2012/21934-9.

2 - Utilizamos a sigla GD ao nos referirmos ao conceito Gestão Democrática.

3 - Esta pesquisa está inserida no projetoConcepções teórico-práticas de educação e trabalho no Movimento dos

Trabalhadores Rurais Sem Terra $(M S T)^{1}$ coordenado pela pesquisadora Prof ${ }^{\mathrm{a}} \mathrm{Dr}^{\mathrm{a}}$ Neusa Maria Dal Ri e conta com financiamento do CNPq.

4 - Sendo eles: Escola Iraci Salete Strozak (em Cantagalo), Escola Ireno Alves dos Santos (em Rio Bonito do Iguaçu) - ambas interligadas ao Centro de Desenvolvimento Sustentável e Capacitação em Agroecologia (CEAGRO) - Escola José Gomes da Silva (em São Miguel do Iguaçu), ${ }^{1}$ Escola Milton Santos (em Maringá) e Escola Latino Americana de Agroecologia (no município da Lapa).

5 - Sobre isso ver Caldart (2012).

\section{REFERÊNCIAS}

CALDART, Roseli Salete. (org.) Caminhos para a transformação escolar. São Paulo: Expressão Popular, 2010.

CALDART, Roseli Salete. Pedagogia do Movimento Sem Terra.4 ed.São Paulo: Expressão Popular, 2012.

CAPORAL, Francisco Roberto; COSTABEBER, José Antônio. Análise multidimensional da sustentabilidade: uma proposta metodológica a partir da Agroecologia. Rev. Agroecologia e Desenvolvimento Rural Sustentável, Porto Alegre, v. 3, n. 3, jul./set. 2002. p.70-85

DAL RI, Neusa Maria; VIEITEZ, CandidoGiraldez. A educação do movimento dos sem terra.Revista Brasileira de Educação, Campinas, v.26, 2004.

DAL RI, Neusa Maria. Educação democrática e trabalho associado no contexto político-econômico do Movimento dos Trabalhadores Rurais sem Terra. 2004. 315 f. Tese (Livre-Docência) - Faculdade de Filosofia e Ciências, Universidade Estadual Paulista, Marília.

DAL RI, Neusa Maria; VIEITEZ, Candido Giraldez.Educação democrática e trabalho associado no Movimento dos Trabalhadores Rurais Sem Terra e nas fábricas de autogestão. 1a.ed. São Paulo: Ícone: FAPESP, 2008. v. 1. 346 p. 2.

ESCOLA MILTON SANTOS. A Escola Milton Santos.Maringá, 2003. Mimeo.

FÉLIX, Maria de F. C. Administração escolar: problema educativo ou empresarial? São Paulo: Cortez, 1989.

GUHUR, Dominique M. P.; TONÁ, Nilciney. Agroecologia. In: CALDART, R.S; PEREIRA, I.B; ALENTEJANO, P; FRIGOTTO, G. (orgs.) Dicionário de educação do campo. Rio de Janeiro, São Paulo: Escola Politécnica de Saúde Joaquim Venâncio, Expressão Popular, 2012. p. 57-66.

GUHUR, Dominique M. P. Contribuições do diálogo de saberes à educação profissional em Agroecologia no MST: desafios da educação do campo na construção do projeto popular. 2010. $265 \mathrm{f}$. Dissertação (Mestrado em Educação) - Universidade Estadual de Maringá, Maringá, 2010.

GUHUR, Dominique M. P. Entrevista. Escola Milton Santos, setembro de 2012.

KUENZER, Acácia Zeneide. As mudanças no mundo do trabalho e a educação: novos desafios para a gestão. In: FERREIRA, N. S. C. Gestão democrática da educação: atuais tendências, novos desafios. São Paulo: Cortez, 1998, p. 33-58.

LIMA,Aparecida do Carmoet al. Reflexão sobre a educação profissional em agroecologia no MST: desafios nos cursos técnicos do Paraná. In: RODRIGUES, F.C; NOVAES, H.T; BATISTA, E. L. (orgs.) Movimentos sociais, trabalho associado e educação para além do capital. São Paulo: Outras Expressões, 2012.

LIMA, Aparecida do Carmo. Práticas educativas em agroecologia no MST/PR: processos formativos na luta pela emancipação humana. 2011. 321 f. Dissertação (Mestrado em Educação) - Universidade Estadual de Maringá, Maringá, 2011.

MST. Princípios da educação no MST. Caderno de Educação, São Paulo, n. 8, p.4-24, 1996. 